Dear Professor Ernest Giralt

Journal of Peptide Science

Thank you very much for your e-mail dated January 16, 2017. On behalf of all authors, I would like to thank the Journal of Peptide Science editorial staff for the handling of our manuscript. The manuscript (Manuscript ID: PSC-16-0198, Title: $N$-terminal diproline and charge group effects on the stabilization of helical conformation in alanine-based short peptides: CD studies with water and methanol as solvent) has been revised in obedience to the reviewer's suggestions as follows.

Very truly yours,

Bhupesh Goyal, Ph.D.

Assistant Professor

Department of Chemistry,

Sri Guru Granth Sahib World University,

Fatehgarh Sahib-140406, Punjab, India

Email: bhupesh@iitbombay.org

\title{
Response to the editor and reviewer's comments
}

Many thanks for the valuable comments, which have helped us to improve the manuscript. Replies to specific queries are as follows:

Editor:

Comment: The peptides were synthesized on resin by standard procedures, but after cleavage from the resin no purification is mentioned. Are the products pure enough to conduct conformational studies?

Response: The peptides were synthesized manually on Rink Amide AM resin using standard Fmoc chemistry and HOBt/DIC as coupling reagents. The purity of the peptides were assessed by high-performance liquid chromatography (HPLC) over reverse-phase (RP) C18 column $(10 \mu \mathrm{M}, 10 \mathrm{~mm} \times 250 \mathrm{~mm}$; Merck) eluting with water/acetonitrile $(0.1 \% \mathrm{TFA}) 5-$ 95\% gradients, and determined to be at least $95 \%$ pure by analytical HPLC. The details regarding purification of the synthesized peptides have been added on page 10 of the revised manuscript.

Comment: Reduce the references number chosing the most representative and show each article separately according to the style of the journal.

Response: As suggested by the editor, the references section of the manuscript has been revised.

This is the author manuscript accepted for publication and has undergone full peer review but has not been through the copyediting, typesetting, pagination and proofreading process, which may lead to differences between this version and the Version of Record. Please cite this article as doi: $10.1002 /$ psc.3005 
Comment: Please, do not use numbering of the residues in the sequence with subscripts.

Response: As suggested by the editor, the numbering of the residues in the sequence with subscripts has been removed in the revised manuscript.

\section{Referee: 1}

\section{Comments:}

The manuscript by Durani et al. reported the effects of N-diproline and charged group on the conformation of Ala-based short peptides. The design and experimental data may be interested to peptide researchers and could be published in this journal. However, the following issues need to be addressed and considered to improve the manuscript.

Comment: Three peptides A1, A2, and A3 were designed and synthesized in this work. However, temperature-dependent and solvent variation experiments were only performed for A1 and A2. How about A3? It is suggested that the authors should add more experimental data for $\mathrm{A} 3$ and interpretation.

Response: In the present study, a cationic peptide Ac-Pro-Pro-Ala-Lys-Ala-Lys-Ala-LysAla- $\mathrm{NH}_{2}$ (A1) was designed to assess the effect of $\mathrm{N}$-terminal diproline and lysine side chains for the inducement of helical conformation. The ion-pair peptides, Ac-Pro-Pro-Glu-

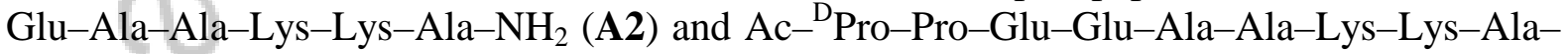
$\mathrm{NH}_{2}$ (A3), were designed to assess the effect of Glu...Lys $(i, \mathrm{i}+4)$ salt bridge interactions on the nucleation of helical conformation.

The folding simulations of all-alanine peptides and a number of short alanine-based helical peptides with positively or negatively charged residues have highlighted the role of hydrophobic interaction and charged side chains in the folding of $\alpha$-helical peptides (Chowdhury, et al., Biopolymers, 2003, 68, 63-75; Pande, et al., Biopolymers, 2003, 68, 91109; Ferrara, et al., Proteins: Struct., Funct., Genet., 2002, 39, 252-260; Snow, et al., Ann. Rev. Biophys. Biomol. Struct., 2005, 34, 43-69). In addition, computer simulations of these short helical alanine-based peptides and the peptides with salt bridge pairs have provided deeper insights into the role of charged side chains in the stability of helical peptides (Garcia, et al., Proc. Natl. Acad. Sci. USA, 2002, 99, 2782-2787; Nymeyer, et al., Proc. Natl. Acad. Sci. USA, 2003, 100, 13934-13939).

The diproline segments have been reported as potential nuclei for initiating helical folding in peptides (Venkatachalapati, et al., Nature, 1979, 281, 83-84). Kemp, et al., have highlighted that covalently constrained diproline surrogate as the effective template for inducing helical conformations in short acyclic sequences (Kemp, et al., Nature, 1991, 352, 451-454; Kemp, et al., J. Org. Chem., 1991, 56, 6683-6697; Kemp, et al., J. Org. Chem., 1991, 56, 6672- 
6682; Job, et al., Angew. Chem., 2004, 116, 5767-5769; Angew. Chem. Int. Ed., 2004, 43, 5649-5651; Heitmann, et al., J. Am. Chem. Soc., 2005, 127, 1690-1704). The main objective of the present study was to address a combined effect of $\mathrm{N}$-terminal diproline and charge groups for possible inducement of helical folds in the de novo designed nonapeptides using CD studies. Thus, a cationic peptide (A1) and an ion-pair peptide (A2) was further selected for the temperature-dependent and solvent variation experiments to assess the effect of positively charged residues and Glu...Lys $(i, i+4)$ salt bridges on the nucleation of helical conformation.

Comment: Since D-Pro was incorporated in A3, what was the effect of D-Pro on peptide conformation? This should be discussed in the main text.

Response: The percentage helical content calculated from the mean residue molar ellipticity at $222 \mathrm{~nm}$ highlight that $\mathbf{A 3}$ sample higher helical content in water than A2 (Table 2). Saha, et al., have investigated conformational states for the diproline segment ( ${ }^{\mathrm{L}}$ Pro- ${ }^{\mathrm{L}}$ Pro) found in 606 protein structures in the non-redundant data set (Saha, et al., Biopolymers, 2012, 97, 5464). The study highlighted that PPII-PPII and PPII- $\alpha$ are the most favorable conformational states for the diproline segment which is consistent with the results of present study that highlight higher PPII content for A2 (N-terminal homochiral diproline, ${ }^{\mathrm{L}}$ Pro- ${ }^{\mathrm{L}}$ Pro, segment) as compare to $\mathbf{A 3}$ (N-terminal heterochiral diproline, ${ }^{\mathrm{D}}$ Pro- ${ }^{\mathrm{L}} \mathrm{Pro}$, segment) which in turn implies lower helical content for $\mathbf{A 2}$ than $\mathbf{A 3}$.

Raghavender investigated linear hydrophobic sequences containing centrally positioned diproline motifs, heterochiral (DL/LD) and homochiral (LL/DD), for their ability to form $\beta$ hairpins (Raghavender, J. Biomol. Struct. Dyn., 2013, 31, 1404-1410). The author reported that the propensity of homochiral diproline segments to adopt PPII conformations is higher than heterochiral segments which are consistent with the results of the present study. DFT calculations highlight that the energetics of folding critically depend on the geometrical relationship between backbone peptide units of the polypeptide structure (Goyal, et al., RSC $A d v ., 2016,6,113611-113619)$. The effect of the orientation of backbone peptide units of polypeptide main-chain on the energetics of folding has been examined with DFT by utilizing end-protected model peptides of LLLL- and DLLL-stereochemical structure. DFT calculations highlighted that enthalpy change and free energy change from an extended state to the folded state is more favourable for Ac- ${ }^{\mathrm{D}}$ Pro- $-{ }^{\mathrm{L}} \mathrm{Pro}-{ }^{\mathrm{L}} \mathrm{Ala}_{2}-\mathrm{NHMe}$ as compare to $\mathrm{Ac}-{ }^{\mathrm{L}} \mathrm{Pro}_{2}-{ }^{\mathrm{L}} \mathrm{Ala}_{2}-$ $\mathrm{NHMe}$ which is consistent with the present results that highlight more helical structures for A3 than A2. Although a number of studies reported diproline segments as potential nuclei for initiating helical folding in peptides, however, the precise role of diproline segments in the nucleation and stabilization of folded structures remain elusive; thus, merits further consideration. The above discussion have been included on page 6 of the revised manuscript.

Comment: The helical content of A2 is smaller than that of A3 in aqueous solution, but it is reversed in methanol. Can the authors add explanation to this? 
Response: The helical content of $\mathbf{A 2}$ is smaller than that of $\mathbf{A 3}$ in water that is consistent with the following studies:

Saha, et al., have investigated conformational states for the diproline segment ( ${ }^{\mathrm{L}}$ Pro- ${ }^{\mathrm{L}}$ Pro) found in 606 protein structures in the non-redundant data set (Saha, et al., Biopolymers, 2012, 97, 54-64). The study highlighted that PPII-PPII and PPII- $\alpha$ are the most favorable conformational states for the diproline segment which is consistent with the results of present study that highlight higher PPII content for A2 (N-terminal homochiral diproline, ${ }^{\mathrm{L}}$ Pro- ${ }^{\mathrm{L}}$ Pro, segment) as compare to $\mathbf{A 3}$ (N-terminal heterochiral diproline, ${ }^{\mathrm{D}}$ Pro- ${ }^{\mathrm{L}} \mathrm{Pro}$, segment) which in turn implies lower helical content for A2 than A3.

Raghavender investigated linear hydrophobic sequences containing centrally positioned diproline motifs, heterochiral (DL/LD) and homochiral (LL/DD), for their ability to form $\beta$ hairpins (Raghavender, J. Biomol. Struct. Dyn., 2013, 31, 1404-1410). The author reported that the propensity of homochiral diproline segments to adopt PPII conformations is higher than heterochiral segments which are consistent with the results of the present study.

DFT calculations highlight that the energetics of folding critically depend on the geometrical relationship between backbone peptide units of the polypeptide structure (Goyal, et al., RSC $A d v ., 2016,6,113611-113619)$. DFT calculations highlighted that enthalpy change and free energy change from an extended state to the folded state is more favourable for Ac- ${ }^{\mathrm{D}}$ Pro${ }^{\mathrm{L}} \mathrm{Pro}-{ }_{\mathrm{L}} \mathrm{Ala}_{2}-\mathrm{NHMe}$ as compare to $\mathrm{Ac}-{ }^{\mathrm{L}} \mathrm{Pro}_{2}-{ }^{\mathrm{L}} \mathrm{Ala}_{2}-\mathrm{NHMe}$ which is consistent with the present results that highlight more helical structures for $\mathbf{A 3}$ than $\mathbf{A 2}$.

The observed variation in the helical content of $\mathbf{A 2}$ as compare to $\mathbf{A 3}$ in methanol can be explained on the basis of change in the N-terminal diproline. Hwang, et al., highlighted that local sequence and environment play a significant role in determining whether methanol tightens or loosens the local protein structure (Hwang, et al., J. Phys. Chem. B, 2011, 115, 6653-6660). The above discussion have been included on page 6,7 of the revised manuscript.

Comment: On page 7, the authors describes that A1 transforms from PPII to beta-strand upon increasing temperature based on CD spectra. Why not disordered structures? Did the authors have any other evidences to support this arguments? How about the temperature effects on A2? This part was not explained clearly.

Response: On raising the temperature, the weak positive maximum at $217-220 \mathrm{~nm}$ observed for A1 disappear, meanwhile the absolute value of negative band at $\sim 197 \mathrm{~nm}$ decreases. The results indicate that a $\beta$-strand conformer become more populated at the expense of PPIIconformer at a higher temperature. In addition, a clear isodichroic point at $\sim 207 \mathrm{~nm}$ was observed. Accordingly, temperature effect in the CD spectrum can be interpreted in terms of a two-state transition between a PPII and a $\beta$-strand conformation in agreement with the result from a CD spectrum of cationic trialanine (Eker, et al., J. Am. Chem. Soc., 2003, 125, 
8178-8185). Srivastava, et al., highlighted that serine nonapeptide, Ac-(Ser-Ala $)_{4}-\mathrm{Ser}-\mathrm{NH}_{2}$, display a PPII-helix conformation in water which unfolds to extended $\beta$-conformation with increase in temperature, apparently in a two-state equilibrium (Srivastava, et al., AIP Advances, 2014, 4, 067140). $\mathrm{Mu}$, et al., performed classical molecular dynamics (MD) studies of trialanine in aqueous solution and highlighted that two extended conformers, $\beta$ and PPII, of AAA coexist in aqueous solution (Mu, et al., J. Phys. Chem. B, 2002, 106, 52945301).

The temperature-dependent CD measurement of poly-L-lysine by Tiffany and Krimm also clearly depicted an isodichroic point reflecting the coexistence of two conformations (Tiffany, et al., Biopolymers, 1968, 6, 1767-1770]. Shi, et al., analyzed the seven-residue alanine peptide (XAO peptide) by NMR and CD spectroscopy and found a transition between PPII (stabilized at low temperature) and $\beta$-strand structure (stabilized at high temperature) (Shi, et al., Proc. Natl. Acad. Sci. U. S. A., 2002, 99, 9190-9195; Shi, et al., Adv. Protein Chem., 2002, 62, 163-240). The authors reported that the increase in ${ }^{3} \mathrm{~J}_{\mathrm{HN} \alpha}$ coupling constant with increase in temperature strongly suggests that $\beta$ strand is the new backbone conformation produced at higher temperatures.

The CD spectrum of A2 measured at different temperatures between $20{ }^{\circ} \mathrm{C}$ and $75{ }^{\circ} \mathrm{C}$ is shown in Fig. 4 (right panel). The spectra display strong negative bands at $\sim 197 \mathrm{~nm}$, however, the ellipticity values are smaller as compare to A1. The absolute value of negative band at $\sim 197 \mathrm{~nm}$ decreases with an increase in temperature and an isodichroic point at $\sim 207$ $\mathrm{nm}$ was observed. The results highlight that a $\beta$-strand conformer become more populated at the expense of PPII-conformer at a higher temperature as observed with A1. The above discussion have been added on page 8,9 of the revised manuscript.

Comment: The solvent variation measurements for A1 indicate the structure changes from PPII to other conformation. What type of other conformation could be? The authors may want to add sentences to explain this.

Response: For better clarity and understanding of the readers, the statement is rephrased as "On increase of methanol concentration, $\mathbf{A 1}$ manifest a shift from the weak positive peak at $\sim 220 \mathrm{~nm}$ and a large negative peak around $197 \mathrm{~nm}$, diagnostic for the PPII structure, to a weak negative shoulder at around $\sim 225 \mathrm{~nm}$ and negative peak at near $204 \mathrm{~nm}$ which highlight the existence of helical folds in the equilibrium ensemble." The rephrase statement is mentioned on page 9 of the revised manuscript. Dalgicdir, et al., highlighted that two synthetic peptides, LKKLLKLLKKLLKL (LK) and EAALAEALAEALAE (EALA), adopt neither random coil nor fully formed $\alpha$-helical structure in water (Dalgicdir, et al., PLoS Comput. Biol. 2015, 11, e1004328). Using molecular dynamics simulations, the authors reported that the peptides adopt multiple conformations with short lifetimes in water. 
Comment: On page 7, line 8 describes "With the increase of methanol concentration....", but in Figure 3, only the peptide concentration is changing. This is very confusing, and needs to be clarified and corrected.

Response: We thank the reviewer for bringing this to our notice. The statement is revised as "With the increase in peptide concentration, no marked change of peak position was observed, however, variation in the intensity of the positive peak at $193 \mathrm{~nm}$ was observed for A1, A2, and A3 (Fig. 3, right panel)" on page 8 of the revised manuscript.

Comment: The authors used the CD spectra at different peptide concentrations to show that there are no peptide oligomers formed in solution. The concentration range is relatively small (40-100 $\mathrm{uM})$ and may not be enough to support the argument. A larger concentration range, such as 10 -fold between lowest and highest, may be more appropriate.

Response: Banerji, et al., observed a red shift in the CD signature of a tetrapeptide constellated with alternative D- and L-proline upon an increase in the peptide concentration in water which highlight the formation of the oligomeric structure of the peptide (Banerji, et al., $R S C A d v ., 2012,2,6744-6747)$. The absence of a red shift in the CD signature of A1, A2, and $\mathbf{A 3}$ on the concentration variation in water indicate that each peptide exists as a monomeric fold in the working concentration regime $(40-100 \mu \mathrm{M})$.

Guarracino, et al., designed and synthesized short 6-8 residue $\alpha$ - and $\beta$-peptides by using primary sequence design features that influence helical control and directly compared the helicity across peptides with the most minimal epitopes (Guarracino, et al., J. Biomol. Struct. Dyn., 2015, 33, 597-605). For each of the peptides studied, the CD signature was examined for three different concentrations of peptide: 25,50 , and $100 \mu \mathrm{M}$. In every case, no remarkable change was seen and the helical signature was identical at every concentration evaluated. The CD spectral results of each peptide indicated that, for this concentration range, the peptides showed near identical signature, signifying a lack of concentration dependence. The above discussion is included on page 7,8 of the revised manuscript.

Comment: The NMR spectra in Fig. S2 are not clear and hard to be read.

Response: As suggested by the reviewer, the NMR spectra in Fig. S2 have been revised for better clarity.

\section{Referee: 2}

\section{Comments:}


In my opinion the data do not support all the author's conclusions and the main objectives of this paper were not completely demonstrated. Additional examples using analogous peptides could be useful to prove the effects of the N-terminal diproline motif on the initiation of the helix. In addition, a more detailed NMR analysis is required for a description of the conformational behaviour of the peptides.

Response: The short sequences of Ala peptides, $\mathrm{Ala}_{\mathrm{n}},(\mathrm{n}=10)$ do not form helices in water (Ingwall, et al., Biopolymers, 1968, 6, 331-368; Platzer, et al., Macromolecules, 1972, 5, 177-187). The NMR data for short polyalanine peptides, $\left(\mathrm{Ala}_{3-7}\right)$, highlighted that the peptides exist as polyproline II (PPII) helix-like structures with very little population in the $\alpha$ helical conformation (Graf, et al., J. Am. Chem. Soc., 2007, 129, 1179-1189).

In the present study, CD studies highlight inducement of helical conformation in a short alanine-based peptides by employing $\mathrm{N}$-terminal diproline and lysine, glutamic acid residues in the $i, i+4$ arrangement which is significant for a peptide of nine-residue length. The results of the present study will enhance our understanding on stabilization of helical conformation in short peptides and hence aid in the design of novel peptides with helical structures.

The CD studies have been employed to assess the conformational behaviour of the short peptides (Guarracino, et al., J. Biomol. Struct. Dyn., 2015, 33, 597-605; Eker, et al., J. Am. Chem. Soc., 2003, 125, 8178-8185). Guarracino, et al., designed and synthesized short 6-8 residue $\alpha$ - and $\beta$-peptides by using primary sequence design features that influence helical control and directly compared the helicity across peptides with the most minimal epitopes (Guarracino, et al., J. Biomol. Struct. Dyn., 2015, 33, 597-605). Using CD spectroscopy, the authors highlighted that both $\alpha$ - and $\beta$-peptides abided by their respective design principles, with no significant "cross-helicity" inducing an $\alpha$ - or a $\beta$-peptide to fold into the oppositely controlled helix. Eker, et al., measured the UV circular dichroism (UVCD) spectra of trialanine dissolved in $\mathrm{D}_{2} \mathrm{O}, \mathrm{H}_{2} \mathrm{O}$, and glycerol (Eker, et al., J. Am. Chem. Soc., 2003, 125, 8178-8185). The results highlight the coexistence of a polyproline II or $33_{1}$-helix and a somewhat disordered flat $\beta$-strand conformation, in complete agreement with predictions from spectroscopic data (Eker, et al., J. Am. Chem. Soc., 2002, 124, 14330-14 341).

\title{
$\mathrm{N}$-terminal diproline and charge group effects on the stabilization of helical conformation in alanine-based short peptides: CD studies with water and methanol as solvent
}

\author{
Bhupesh Goyal, ${ }^{*[a, b]}$ Kinshuk Raj Srivastava, ${ }^{[a, c]}$ and Susheel Durani ${ }^{*[a]}$
}


[a] Dr. Bhupesh Goyal, Dr. Kinshuk R. Srivastava, Prof. Susheel Durani

Department of Chemistry, Indian Institute of Technology Bombay, Powai, Mumbai400076, India

E-mail: bhupesh@iitbombay.org; sdurani@iitb.ac.in

\section{Present address}

[b] Dr. Bhupesh Goyal

Department of Chemistry, School of Basic and Applied Sciences, Sri Guru Granth Sahib World University, Fatehgarh Sahib-140406, Punjab, India

[c] Dr. Kinshuk R. Srivastava

Life Sciences Institute, University of Michigan, Ann Arbor, MI, USA, 48105.

This article is protected by copyright. All rights reserved. 


\begin{abstract}
Protein folding problem remains a formidable challenge as main chain, side chain and solvent interactions remain entangled and have been difficult to resolve. Alanine-based short peptides are promising models to dissect protein folding initiation and propagation structurally as well as energetically. The effect of $\mathrm{N}$-terminal diproline and charged side chains are assessed on the stabilization of helical conformation in alanine-based short peptides using Circular dichroism (CD) with water and methanol as solvent. A1 (Ac-Pro-Pro-Ala-Lys-Ala-LysAla-Lys-Ala- $\left.\mathrm{NH}_{2}\right)$ is designed to assess the effect of $\mathrm{N}$-terminal homochiral diproline and lysine side chains for the inducement of helical conformation. A2 (Ac-Pro-Pro-Glu-GluAla-Ala-Lys-Lys-Ala-NH 2 ) and A3 (Ac- ${ }^{\text {D Pro-Pro-Glu-Glu-Ala-Ala-Lys-Lys-Ala-NH }}$ ) with $\mathrm{N}$-terminal homochiral and heterochiral diproline, respectively, are designed to assess the effect of Glu...Lys $(i, i+4)$ salt bridge interactions on the stabilization of helical conformation. The CD spectra of A1, A2, and $\mathbf{A 3}$ in water manifest different amplitudes of the observed PPII signals which indicate different conformational distributions of the polypeptide structure. The strong effect of solvent substitution from water to methanol is observed for the peptides and CD spectra in methanol evidence A2 and A3 as helical folds. Temperature-dependent CD spectra of $\mathbf{A 1}$ and $\mathbf{A} \mathbf{2}$ in water depict an isodichroic point reflecting coexistence of two conformations, PPII and $\beta$-strand conformation, which is consistent with the previous studies. The results illuminate the effect of N-terminal diproline and charged side chains in dictating the preferences for extended- $\beta$, semi-extended PPII and helical conformation in alanine-based short peptides. The results of the present study will enhance our understanding on stabilization of helical conformation in short peptides and hence aid in the design of novel peptides with helical structures.
\end{abstract}

Keywords: Alanine-based peptides; circular dichroism; helical conformation; N-terminal diproline; polyproline II (PPII) conformation; protein folding 


\section{Introduction}

Prot eins are characterized by the abil ity to adopt unique folds specif ic for their sequences [1]. The folds are specified sequent ially and characterizing the basis remains a grand challenge given the size of a typical protein and the complexity of it s interactions [2-4]. The problem has been addressed using bottom up a pproach of simple to incrementally compl ex model s. The models are designed to observe the confor mat ional prefer ences of the pol ypept ide cha in and addressing the basis with theory using computat ional model ing [5-7]. The empir ical force fields have been applied for simulation of equil ibr ia to address the ther modynamics with r igor [8-10]. Much research has been r eported in recent years with ol igoalanine as the protein ma in cha in model s [11-15]. The model s have establ ished that unfolded proteins tend to adopt appreciable order as semi-extended structures in correspondence of PPII confor mat ion [16$18]$.

In the interest of protein folding problem, it is useful to perturb ol igoalanine model with effects such as to induce their order ing as specif ic folds to character ize the effect with both ex per iment as well as theory. Spec if ically, dissect ion of effects that concern the int eractions of the main chain against interactions of side chains evokes interest. The stereochemical effect of N-ter minal modificat ion that is ca pable of influencing confor mat ion at the level of ma in chain structure [19-21], and the role of residue st ereochemistry in the del ineation of protein folding mechanism [22], to increase the stabil ty of proteins [23], to redesign an active and specific ion channel [24], and in the design of novel folds is highl ight ed in the literature [25-29]. The electrostat ic interact ions among ma in cha in as well as side chains are well recognized for their role in promoting conformational folding in the polypeptide structure [30,31].

The helical fold is of paramount importance in protein folding research as it constitute major secondary structure found in natural proteins and control numerous biological activities and functions $[32,33]$. The helical fold plays a key role in the vast majority of proteins that are found in the cell and is often found at the interface between proteins mediating proteinprotein interactions [34]. The misregulation of helical promoted interactions leads to the 
disease state. Thus, a better understanding of the helical structure and the elucidation of the factors that dictate its structure and stabilization is of key importance.

The folding simulations of all-alanine peptides and a number of short alanine-based helical peptides with positively or negatively charged residues have highlighted the role of hydrophobic interaction and charged side chains in the folding of $\alpha$-helical peptides [35]. The diproline segments, covalently constrained diproline surrogate have been reported as potential nuclei for initiating helical folding in peptides [36-38]. The present study addresses nonapeptide composed of L-amino acids for the effect in $\mathrm{N}$-terminal diproline and chargegroup effect over side chains that are capable of ordering the peptide as a helical fold. Due to charged side chains, nonapeptides are water soluble and hence amenable to experiment. The peptides were designed, synthesized and examined with Circular dichroism (CD) to assess the possible contribution of extended- $\beta$, semi-extended PPII and helical conformation in the equilibrium ensemble. Subtle variations of these conformational possibilities are indicated in the designed peptides with CD. CD spectral studies have been employed to identify stable and nascent secondary structure in short peptide fragments which lack tertiary interactions in a number of studies [39-41]. The implications for the understanding of nucleation and stabilization of helical conformation are discussed. The results of the present study will aid in the design of novel peptides with helical structures. The role of helical structures in the rational design of biocompatible hydrogels and inhibition of disease-relevant intracellular or extracellular protein-protein interactions have been reported in the literature $[42,43]$.

\section{Results and discussion}

\section{Design, synthesis and characterization of peptides}

The study is implemented with nineresidue pept ides (Table 1). The models are primarily ol igoalanine sequences having intrinsically hel ix favoring residue [44]. The model ol igoalanine is subst tuted with internal Lys and Gl u residues for impart ing solubil ty. The Nterminal dialanine is subst ituted with a diprol ine segment of homochiral and heterochiral structure for possible inducement of hel ical confor mat ion. The diprol ine seg ment, coval ently 
constrained diprol ine surrogate have been empl oyed as potent ial nuclei for inducing hel ical confor mat ions in peptides [36-38]. Thus, a combinat ion of charge-group effect over side chains and stereochemical effect of the N-terminal structure are examined for possible inducement of hel ical folds.

A1 is designed to assess the effect of Nter minal homochiral diprol ine segment and lysine side chains for the inducement of hel ical conformation. A2 and A3, with N-terminal homochiral and het erochiral diprol ine segment,r espect ivel y, ar e designed to assess the effect of Glu...Lys $(i, i+4)$ salt br idge int eract ions on the nucl eat ion of hel ical confor mat ion. The designed pept ides were synthesized by manual sol id-phase synthesis using standard Fmocchemistry. The peptides displayed expected MS peaks in QTOF-ESI-MS, m/z 922 for A1, m/z 981 for $\mathbf{A} 2$ and A3 (Fig. S1). ${ }^{1}$ H NMR spectra for A1, A2, and A3 recorded at $2.5 \mathrm{mM}$ concentrat ion in $90 \% \mathrm{H}_{2} \mathrm{O} / 10 \% \mathrm{D}_{2} \mathrm{O}$ at $298 \mathrm{~K}$ are present ed in Fig. S2. ${ }^{1} \mathrm{H}$ NMR spectra were recorded at ten fold dil ution for each pept ide. No not iceable dilut ion effect on chemical shifts or 1 ine widths were observed for the synthesized pept ides. This indicates that the peptides do not aggregate in the concentrat ion regime of NMR ex periment. A2 and A3 manifest similar ${ }^{1} \mathrm{H}-\mathrm{NMR}$ spectra except in their NH regions in accordance with stereochemically differentiated structure of the peptides (Fig. S2). NMR spectra in methanol were characterized by a pparent rapid solvent exchange r esult ing in non-observat ion of a mide-NH resonances. Ther efore, no further NMR studies were pur sued in methanol .

\section{Characterization of conformation of peptides in water}

The CD spectra of peptides A1, A2, and A3 in water are displayed in Fig. 1. The spectrum of A1 is characterized by a weak positive peak at $\sim 220 \mathrm{~nm}$ and a sharp negative peak below 200 $\mathrm{nm}$. In the absence of interfering signals from aromatic side chains, such a couplet is characteristic for the PPII conformation [45-47]. The CD spectrum of A1 in water resembles the pattern that Kallenbach and co-workers characterized as a signature for PPII helix [18]. Banerji, et al., reported that tetrapeptide constellated with alternative D- and L-proline displayed a negative CD band at $\sim 199 \mathrm{~nm}$ which highlight that peptide exists in the PPII 
conformation [48]. The weak positive maximum at $217-220 \mathrm{~nm}$ is the most pronounced for A1 which suggest that $\mathbf{A 1}$ has, relatively, the highest contribution of the PPII-like conformer.

As shown in Fig. 1, the small positive maximum at $~ 220$ disappear and the absolute value of negative band at $\sim 197 \mathrm{~nm}$ decreases along with $\sim 1 \mathrm{~nm}$ redshift for $\mathbf{A 2}$ and A3. In addition to the negative band at $\sim 197 \mathrm{~nm}$ for A3, we observe a broad negative shoulder at $\sim 224 \mathrm{~nm}$ for A3 which highlight existence of other conformational folds in the equilibrium ensemble. Thus, observation of variation in the level of ordering of PPII conformation imply the equilibrium that involves the participation of other conformational folds which highlight the role of N-terminal diproline and Glu...Lys salt bridge interactions in the conformational landscape of the designed peptides. The participation of other conformational folds is evident from the percentage helical content calculated from the mean residue molar ellipticity at 222 $\mathrm{nm}$ which highlight that $\mathbf{A 2}$ and $\mathbf{A 3}$ sample helical conformation, i.e., 9\% and 26\%, respectively (Table 2). The ellipticity at $222 \mathrm{~nm}$ has been employed to estimate the $\alpha$-helix content from CD spectra in a number of studies $[49,50]$.

Saha, et al., have investigated conformational states for the diproline segment ( ${ }^{\mathrm{L}}$ Pro- ${ }^{\mathrm{L}}$ Pro) found in 606 protein structures in the non-redundant data set [51]. The study highlighted that PPII-PPII and PPII- $\alpha$ are the most favorable conformational states for the diproline segment which is consistent with the results of present study that highlight higher PPII content for A2 as compare to A3 which in turn implies lower helical content for A2 than A3.

Raghavender investigated linear hydrophobic sequences containing centrally positioned diproline motifs, heterochiral (DL/LD) and homochiral (LL/DD), for their ability to form $\beta$ hairpins [52]. The author reported that the propensity of homochiral diproline segments to adopt PPII conformations is higher than heterochiral segments which is consistent with the results of the present study. DFT calculations highlight that the energetics of folding critically depend on the geometrical relationship between backbone peptide units of the polypeptide structure [21]. The effect of the orientation of backbone peptide units of polypeptide mainchain on the energetics of folding has been examined with DFT by utilizing end-protected 
model peptides of LLLL- and DLLL-stereochemical structure. DFT calculations highlighted that enthalpy change and free energy change from an extended state to the folded state is more favourable for Ac- ${ }^{\mathrm{D}}$ Pro- ${ }^{\mathrm{L}}$ Pro- $-{ }^{\mathrm{L}} \mathrm{Ala}_{2}-\mathrm{NHMe}$ as compare to Ac- ${ }^{\mathrm{L}} \mathrm{Pro}_{2}-{ }^{\mathrm{L}} \mathrm{Ala}_{2}-\mathrm{NHMe}$ which is consistent with the present results that highlight more helical structures for $\mathbf{A 3}$ than A2.

Effect of solvent on the conformation of peptides

The alcohols, methanol and trifluoroethanol (TFE), have been extensively used in the protein folding and structure examinations by experimental approaches such as NMR, CD, Fourier transform infrared spectroscopy (FTIR), light scattering, fluorescence etc [53,54]. Methanol plays an important role as a raw material or solvent in numerous enzymatic syntheses due to its low cost and easily supplied industrial organic solvent [55]. Thus characterization of the conformation of peptides in methanol is of key importance.

The strong effect of solvent substitution from water to methanol is observed on the conformation of A1, A2, and $\mathbf{A 3}$ as shown in Fig. 2. With reduced polarity and dielectric strength of methanol as solvent, mutual interactions of suitably placed charged side chains could affect conformation.

As depicted in Fig. 2, CD spectra in methanol evidence $\mathbf{A 2}$ and $\mathbf{A 3}$ as helical folds specifically on the basis of observation of two strong negative bands at $\sim 205 \mathrm{~nm}$ and $\sim 224$ $\mathrm{nm}$ and a positive band at $\sim 193 \mathrm{~nm}$ [56]. Thus, there is a combined effect of N-terminal diproline and Glu...Lys salt bridge in the ordering of $\mathbf{A} 2$ to helical conformation in methanol. The negative bands at $\sim 205 \mathrm{~nm}$ and $\sim 224 \mathrm{~nm}$ for A2 are much more pronounced which suggest that the content of the helical structure is highest for $\mathbf{A 2}$ (Fig. 2, Table 2). Hwang, et al., highlighted that local sequence and environment play a significant role in determining whether methanol tightens or loosens the local protein structure [49]. The observed variation in the helical content of $\mathbf{A 2}$ as compare to $\mathbf{A 3}$ in methanol can be explained on the basis of change in the $\mathrm{N}$-terminal diproline segment. The ratio $(R)$ of the two negative maxima of the ellipticity, $R=[\theta]_{222} /[\theta]_{207}$, has been employed to estimate the helical type (whether $3_{10}$-helix 
or $\alpha$-helix) [57-59]. For $\mathbf{A} 2$ and $\mathbf{A 3}$, the ratio $(R)$ is 0.57 and 0.56, respectively, which highlights that $\mathbf{A} \mathbf{2}$ and $\mathbf{A} \mathbf{3}$ adopt $3{ }_{10}$ helical conformations in methanol.

\section{Lack of concentration dependence observed by CD spectroscopy}

For each peptide A1, A2, and A3, CD signature was examined at four different concentration of the peptide: $40,60,80$, and $100 \mu \mathrm{M}$ in water as well as in methanol. For each peptide, no remarkable change was observed and CD signature was identical at every concentration in water (Fig. 3, left panel). These CD spectral results of A1, A2, and A3 indicate that, for this concentration range, the peptides display near identical signature, signifying a lack of concentration dependence (Fig. 3, left panel). Banerji, et al., observed a red shift in the CD signature of a tetrapeptide constellated with alternative D- and L-proline upon an increase in the peptide concentration in water which highlights the formation of the oligomeric structure of the peptide [48]. The absence of a red shift in the CD signature of $\mathbf{A 1}, \mathbf{A 2}$, and $\mathbf{A 3}$ on concentration variation in water indicate that each peptide exists as a monomeric fold. Guarracino, et al., designed and synthesized short 6-8 residue $\alpha$ - and $\beta$-peptides by using primary sequence design features that influence helical control and directly compared the helicity across peptides with the most minimal epitopes [60]. The CD signature was examined for three different concentration of synthesized peptides, i.e., 25, 50, and $100 \mu \mathrm{M}$. No remarkable change was seen in the CD signature of the synthesized peptides and helical signature was identical at every concentration. The peptides display near identical CD signature signifying a lack of concentration dependence for this concentration range.

With the increase in peptide concentration, no marked change of peak position was observed, however, variation in the intensity of the positive peak at $193 \mathrm{~nm}$ was observed for A1, A2, and A3 (Fig. 3, right panel). The minimum at $\sim 205, \sim 224 \mathrm{~nm}$ and a maximum at $\sim 193 \mathrm{~nm}$ represent helical structures and the absolute values at these points indicate the percentage of helical residues in the peptide. The variation in the intensity of the positive peak at $193 \mathrm{~nm}$ thus highlights minor changes in the percentage of helical residues in the designed peptides. Any change in the helical signature as a result of concentration variation designate potential helical oligomerization [61]. Thus, based on these results no oligomerization appeared to 
occur in the synthesized peptides in methanol and hence each peptide fold is monomeric in concentration regime of $\mathrm{CD}$ experiment in both water and methanol which is consistent with the results from the NMR spectra as well.

\section{Effect of temperature and solvent variation on the conformation of peptides}

The main objective of the present study was to address a combined effect of N-terminal diproline and charge groups for the possible inducement of helical folds in the de novo designed nonapeptides using CD studies. Thus, a cationic peptide (A1) and a ion-pair peptide (A2) was selected for the temperature-dependent and solvent variation experiments to assess the effect of positively charged residues and Glu...Lys $(i, i+4)$ salt bridges on the nucleation of helical conformation. The CD spectrum of $\mathbf{A 1}$ and $\mathbf{A} 2$ in water measured at different temperatures between $20^{\circ} \mathrm{C}$ and $75^{\circ} \mathrm{C}$ at an interval of $5^{\circ} \mathrm{C}$ is shown in Fig. 4 .

On raising the temperature, the weak positive maximum at $217-220 \mathrm{~nm}$ observed for A1 disappear, meanwhile the absolute value of negative band at $\sim 197 \mathrm{~nm}$ decreases. The results indicate that a $\beta$-strand conformer become more populated at the expense of PPII-conformer at a higher temperature. In addition, a clear isodichroic point at $\sim 207 \mathrm{~nm}$ was observed. Accordingly, temperature effect in the CD spectrum can be interpreted in terms of a two-state transition between a PPII and a $\beta$-strand conformation in agreement with the result from a CD spectrum of cationic trialanine [62]. Srivastava, et al., highlighted that serine nonapeptide, Ac-(Ser-Ala $)_{4}-\mathrm{Ser}-\mathrm{NH}_{2}$, display a PPII-helix conformation in water which unfolds to extended $\beta$-conformation with increase in temperature, apparently in a two-state equilibrium [63]. Mu, et al., performed classical molecular dynamics (MD) studies of trialanine in aqueous solution and highlighted that two extended conformers, $\beta$ and PPII, of AAA coexist in aqueous solution [64]. Temperature-dependent CD measurement of poly-Llysine by Tiffany and Krimm also clearly depicted an isodichroic point reflecting the coexistence of two conformations [65]. Shi, et al., analyzed the seven-residue alanine peptide (XAO peptide) by NMR and CD spectroscopy and found a transition between PPII (stabilized at low temperature) and $\beta$-strand structure (stabilized at high temperature) [18]. 
The CD spectrum of $\mathbf{A 2}$ measured at different temperatures between $20{ }^{\circ} \mathrm{C}$ and $75{ }^{\circ} \mathrm{C}$ is shown in Fig. 4 (right panel). The spectra display strong negative bands at $\sim 197 \mathrm{~nm}$, however, the ellipticity values are smaller as compare to A1. The absolute value of negative band at $\sim 197 \mathrm{~nm}$ decreases with an increase in temperature and an isodichroic point at $\sim 207$ $\mathrm{nm}$ was observed. The results highlight that a $\beta$-strand conformer become more populated at the expense of PPII-conformer at a higher temperature as observed with A1.

On increase of methanol concentration, A1 manifest a shift from the weak positive peak at $\sim 220 \mathrm{~nm}$ and a large negative peak around $197 \mathrm{~nm}$, diagnostic for the PPII structure, to a weak negative shoulder at around $\sim 225 \mathrm{~nm}$ and negative peak at near $204 \mathrm{~nm}$ which highlight the existence of helical folds in the equilibrium ensemble (Fig. 5). A2 manifest a clear transition from the PPII-conformer to the helical conformation on increase of methanol concentration on account of the observation of strong negative bands at $\sim 205 \mathrm{~nm}$ and 224 $\mathrm{nm}$ which highlight the role of $\mathrm{N}$-terminal diproline segment as well as Glu...Lys $(i, i+4)$ salt bridge interaction on the nucleation of helical conformation.

\section{Conclusions}

In the present study, the effect of N-terminal diproline and charged side chains in the alaninebased short peptides has been investigated as an approach to scrutinize the specific role of interactions within the main chain and between side chains in inducement and stabilization of helical conformation. The subtle variations in the intensity of CD bands characterizing PPII signature were observed for the model peptides in water which highlight contribution of other conformational states of the polypeptide structure in the equilibrium ensemble. Temperaturedependent CD studies in water provided clear evidence that PPII ensemble will melt to extended $\beta$-conformation with an increase in temperature which is consistent with previous studies. Solvent-dependent CD spectra indicate a transition from PPII-conformer to helical conformation for $\mathbf{A 2}$ which illustrate the role of $\mathrm{N}$-terminal diproline segment as well as Glu...Lys $(i, i+4)$ salt bridge interactions on the nucleation of helical conformation in alanine-based short peptides. The present study will enhance our understanding on the 
stabilization of helical conformation in short peptides and hence aid in the design of novel peptides with helical structures.

\section{Experimental section}

\section{Materials}

Fmoc-protected amino acids, reagents for solid-phase peptide synthesis, Rink-Amide AM resin, dried solvents-dimethylformamide (DMF), methanol, diethylether, dichloromethane were purchased either from Sigma-Aldrich or Novabiochem-Merck.

\section{Peptide Synthesis}

The peptides were synthesized manually on Rink-Amide AM resin as solid support using standard Fmoc chemistry and HOBt/DIC as coupling reagents [66]. The coupling reaction was monitored with standard Kaiser and chloranil tests, each coupling reaction typically required about 6 hrs. Subsequent deprotection step was carried out by 30\% (v/v) piperidineDMF solution. N-terminal was acetylated $\left(-\mathrm{NHCOCH}_{3}\right)$ with $\mathrm{Ac}_{2} \mathrm{O}$ : DIPEA: DMF in 1:2:20 ratio. The cleavage of the end-protected final polypeptide and simultaneous deprotection of side chains were accomplished with reagent $\mathrm{K} \quad(82.5 \%$ TFA/5\% dry-phenol/5\% thioanisole $/ 2.5 \%$ ethandithiol $/ 5 \%$ water). The filtrate from the resin was precipitated with anhydrous diethyl ether and lyophilized in $1: 4 \mathrm{H}_{2} \mathrm{O}:{ }^{\mathrm{t}} \mathrm{BuOH}$ solution to obtain peptide in powdered form. The purity of the peptides were assessed by high-performance liquid chromatography (HPLC) over reverse-phase (RP) C18 column $(10 \mu \mathrm{M}, 10 \mathrm{~mm} \times 250 \mathrm{~mm}$; Merck) eluting with water/acetonitrile (0.1\% TFA) 5-95\% gradients and determined to be at least $95 \%$ pure by analytical HPLC.

\section{Mass Spectra}

Mass spectra of the synthesized peptides were recorded on QTOF-ESI mass spectrometer. Positive ions were detected in linear/reflectron mode.

Nuclear Magnetic Resonance (NMR) 
${ }^{1} \mathrm{H}$ NMR experiments were recorded on Bruker $700 \mathrm{MHz}$ spectrometer at $298 \mathrm{~K}$. Peptide concentration of $2.5 \mathrm{mM}$ was used. The solutions were prepared in $90 \% \mathrm{H}_{2} \mathrm{O} / 10 \% \mathrm{D}_{2} \mathrm{O}$ with 4, 4-dimethyl-4-silapentane-1-sulfonic acid (DSS) as an internal reference. The $1 \mathrm{D}{ }^{1} \mathrm{H}$ spectra were recorded for all peptides at 10 -fold dilution to check the formation of aggregates.

\section{Circular Dichroism (CD)}

CD measurements were performed on JASCO J-180 CD spectropolarimeter calibrated with D-(+)-10-camphorsulfonic acid (CSA). Data were collected at $298 \mathrm{~K}$ in $0.2 \mathrm{~cm}$ path length quartz cell with $2 \mathrm{~nm}$ bandwidth in far-UV (190-250 nm) range. Scanning was done at 100 $\mathrm{nm} / \mathrm{min}$ with $1.0 \mathrm{~s}$ time constant, in $1 \mathrm{~nm}$ steps, and five scans were averaged after background subtraction for solvent water. Because of lack of aromatic residues in the designed peptides, the peptide concentration was determined using the UV absorbance $\left(\mathrm{A}_{205}\right)$ at $205 \mathrm{~nm}[67,68]$. The observations in millidegree ellipticity were converted to mean residue molar ellipticity $[\theta]_{\mathrm{MRW}}$.

\section{Acknowledgements}

We acknowledge Department of Science \& Technology (09DST028), Government of India for financial support and Department of Chemistry, IIT Bombay, Mumbai for the research facilities. Bhupesh Goyal gratefully acknowledges Science and Engineering Research Board (SERB), Department of Science \& Technology, Government of India for the award of SERB Start-Up Research Grant (Young Scientists) (Sanction No: SB/FT/CS-013/2014).

\section{Supporting Information}

The supporting information contains HRMS, ${ }^{1} \mathrm{H}-\mathrm{NMR}$ spectra of the synthesized peptides.

\section{References}

[1] C. B. Anfinsen and H. A. Scheraga, Adv. Protein Chem., 1975, 29, 205-300.

[2] Y. Cote, G. G. Maisuradze, P. Delarue, H. A. Scheraga and P. Senet, J. Phys. Chem. Lett., 2015, 6, 1082-1086. 
[3] P. G. Wolynes, Biochimie, 2015, 119, 218-230.

[4] S. W. Englander and L. Mayne, Proc. Natl. Acad. Sci. U.S.A., 2014, 111, 1587315880 .

[5] M. Compiani and E. Capriotti, Biochemistry, 2013, 52, 8601-8624.

[6] W-Z. Wang, T. Lin and Y-C. Sun, J. Phys. Chem. B, 2007, 111, 3508-3514.

[7] T. Ghosh, S. Garde and A. E. García, Biophys. J., 2003, 85, 3187-3193.

[8] R. Raucci, G. Colonna, G. Castello and S. Costantini, Int. J. Pept. Res. Ther., 2013, 19, $117-123$.

[9] B. R. Brooks et al., J. Comput. Chem., 2009, 30, 1545-1614.

[10] R. B. Best and G. Hummer, J. Phy. Chem. B, 2009, 113, 9004-9015.

[11] J. C. Schulz, M. S. Miettinen and R. R. Netz, J. Phys. Chem. B, 2015, 119, 4565-4574.

[12] C. Liu, J. W. Ponder and G. R. Marshall, Proteins: Struct., Funct., Bioinf., 2014, 82, 3043-3061.

[13] M. Rossi, V. Blum, P. Kupser, G. von Helden, F. Bierau, K. Pagel, G. Meijer and M. Scheffler, J. Phys. Chem. Lett., 2010, 1, 3465-3470.

[14] K. R. Srivastava, A. Kumar, B. Goyal and S. Durani, J. Phys. Chem. B, 2011, 115, 6700-6708.

[15] A. Kumar, V. Ramakrishnan, R. Ranbhor, K. Patel and S. Durani, J. Phys. Chem. B, 2009, 113, 16435-16442.

[16] J. Makowska, S. Rodziewicz-Motowildo, K. Baginska, J. A. Vila, A. Liwo, L. Chmurzynski and H. A. Scheraga, Proc. Natl. Acad. Sci. U.S.A., 2006, 103, 1744-1749.

[17] V. Ramakrishnan, R. Ranbhor and S. Durani, J. Am. Chem. Soc., 2004, 126, 1633216333. 
[18] Z. Shi, C. A. Olson, G. D. Rose, R. L. Baldwin and N. R. Kallenbach, Proc. Natl. Acad. Sci. U. S. A., 2002, 99, 9190-9195.

[19] B. Goyal, A. Kumar, K. R. Srivastava and S. Durani, J. Biomol. Struct. Dyn., 2016, http://dx.doi.org/10.1080/07391102.2016.1199972.

[20] B. Goyal, A. Kumar, K. R. Srivastava and S. Durani, RSC Adv., 2016, 6, 74162-74176.

[21] B. Goyal, K. R. Srivastava, A. Kumar, G. N. Patwari and S. Durani, RSC Adv., 2016, 6, 113611-113619.

[22] R. M. Culik, S. Annavarapu, V. Nanda and F. Gai, Chem. Phys., 2013, 422, 131-134.

[23] A. Rodriguez-Granillo, S. Annavarapu, L. Zhang, R. L. Koder and V. Nanda, J. Am. Chem. Soc., 2011, 133, 18750-18759.

[24] F. I. Valiyaveetil, M. Sekedat, R. MacKinnon and T. W. Muir, Proc. Nat. Acad. Sci. U.S.A., 2004, 101, 17045-17049.

[25] M. D. Struthers, R. P. Cheng and B. Imperiali, Science, 1996, 271, 342-345.

[26] B. Goyal, K. R. Srivastava, K. Patel and S. Durani, ChemistrySelect, 2016, 1, 20502057.

[27] B. Goyal, K. Patel, K. R. Srivastava and S. Durani, RSC Adv., 2015, 5, 105400-105408.

[28] K. Patel, B. Goyal, A. Kumar, N. Kishore and S. Durani, J. Phys. Chem. B, 2010, 114, 16887-16893.

[29] S. Durani, Acc. Chem. Res., 2008, 41, 1301-1308.

[30] E. G. Baker, G. J. Bartlett, M. P. Crump, R. B. Sessions, N. Linden, C. F. Faul and D. N. Woolfson, Nat. Chem. Biol., 2015, 11, 221-228.

[31] Y. Gao, Y. Li, L. Mou, B. Lin, J. Z. H. Zhang and Y. Mei, Sci. Rep., 2015, 5, 1035910364.

[32] A. C. Engler, H. I. Lee, P. T. Hammond, Angew. Chem., 2009, 121, 9498-9502; Angew. Chem. Int. Ed., 2009, 48, 9334-9338. 
[33] N. Hadjichristidis, H. Iatrou, M. Pitsikalis and G. Sakellariou, Chem. Rev., 2009, 109, 5528-5578.

[34] A. M. Watkins, M. G. Wuo and P. S. Arora, J. Am. Chem. Soc., 2015, 137, 1162211630.

[35] C. D. Snow, E. J. Sorin, Y. M. Rhee and V. S. Pande, Ann. Rev. Biophys. Biomol. Struct., 2005, 34, 43-69.

[36] Kantharaju, S. Raghothama, S. Aravinda, N. Shamala and P. Balaram, Biopolymers, 2010, 94, 360-370.

[37] G. E. Job, B. Heitmann, R. J. Kennedy, S. M. Walker and D. S. Kemp, Angew. Chem., 2004, 116, 5767-5769; Angew. Chem. Int. Ed., 2004, 43, 5649-5651.

[38] B. Heitmann, G. E. Job, R. J. Kennedy, S. M. Walker and D. S. Kemp, J. Am. Chem. Soc., 2005, 127, 1690-1704.

[39] M. Inayathullah and J. Rajadas, Neuropeptides, 2016, 57, 9-14.

[40] M. A. Hossain, R. A. D. Bathgate, C. K. Kong, F. Shabanpoor, S. Zhang, L. M. Haugaard-Jçnsson, K. J. Rosengren, G. W. Tregear and J. D. Wade, ChemBioChem, 2008, 9, 1816-1822.

[41] M. Bellanda, S. Mammi, S. Geremia, N. Demitri, L. Randaccio, Q. B. Broxterman, B. Kaptein, P. Pengo, L. Pasquato and P. Scrimin, Chem. Eur. J., 2007, 13, 407-416.

[42] M. Pelay-Gimeno, A. Glas, O. Koch and T. N. Grossmann, Angew. Chem., 2015, 127, 9022-9054; Angew. Chem. Int. Ed., 2015, 54, 8896-8927.

[43] K. Estieu-Gionnet and G. Guichard, Expert Opin. Drug Discovery, 2011, 6, 937-963.

[44] E. J. Spek, C. A. Olson, Z. Shi and N. R. Kallenbach, J. Am. Chem. Soc., 1999, 121, 5571-5572.

[45] J. L. Lopes, A. J. Miles, L Whitmore and B. A. Wallace, Protein Sci., 2014, 23, 17651772 .

[46] R. W. Woody, J. Am. Chem. Soc., 2009, 131, 8234-8245. 
[47] N. R. Kallenbach, P. C. Lyu and H. Zhou, in Circular Dichroism and the Conformation Analysis of Biomolecules, ed. G. D. Fasman, Plenum, New York, 1996, p. 201.

[48] B. Banerji, S. K. Pramanik, U. Pal and N. C. Maiti, RSC Adv., 2012, 2, 6744-6747.

[49] S. Hwang, Q. Shao, H. Williams, C. Hilty and Y. Q. Gao, J. Phys. Chem. B, 2011, 115, 6653-6660.

[50] V. Munoz, F. J. Blanco and L. Serrano, Protein Sci., 1995, 4, 1577-1586.

[51]"I. Saha and N. Shamala, Biopolymers, 2012, 97, 54-64.

[52] U. S. Raghavender, J. Biomol. Struct. Dyn., 2013, 31, 1404-1410.

[53] D. B. Kony, P. H. Hunenberger and W. F. van Gunsteren, Protein Sci., 2007, 16, 11011118 .

[54] M. Perham, J. Liao and P. Wittung-Stafshede, Biochemistry, 2006, 45, 7740-7749.

[55] C. H. Kuo, L. T. Peng, S. C. Kan, Y. C. Liu and C. J. Shieh, Bioresour. Technol., 2013, 145, 229-232.

[56] G. Holzwarth and P. Doty, J. Am. Chem. Soc., 1965, 87, 218-228.

[57] A. Dalzini, C. Bergamini, B. Biondi, M. D. Zotti, G. Panighel, R. Fato, C. Peggion, M. Bortolus and A. L. Maniero, Sci. Rep., 2016, 6, 24000.

[58] F. Formaggio, M. Crisma, P. Rossi, P. Scrimin, B. Kaptein, Q. B. Broxterman, J. Kamphuis and C. Toniolo, Chem. Eur. J., 2000, 6, 4498-4504.

[59] M. C. Manning and R. W. Woody, Biopolymers, 1991, 31, 569-586.

[60] D. A. Guarracino, A. M. Alabanza, C. T. Robertson and S. S. Sanghvi, J. Biomol. Struct. Dyn., 2015, 33, 597-605.

[61] J. X. Qiu, E. J. Petersson, E. E. Matthews and A. Schepartz, J. Am. Chem. Soc., 2006, 128, 11338-11339.

This article is protected by copyright. All rights reserved. 
[62] F. Eker, K. Griebenow and R. Schweitzer-Stenner, J. Am. Chem. Soc., 2003, 125, $8178-8185$.

[63] K. R. Srivastava and S. Durani, AIP Advances, 2014, 4, 067140.

[64] Y. Mu and G. Stock, J. Phys. Chem. B, 2002, 106, 5294-5301.

[65] M. L. Tiffany and S. Krimm, Biopolymers, 1968, 6, 1767-1770.

[66] W. C. Chan and P. D. White, Fmoc Solid Phase Peptide Synthesis: A Practical Approach, Oxford University Press, U.S.A., 2000.

[67] R. K. Scopes, Anal. Biochem., 1974, 59, 277-282.

[68] G. R. Grimsley and C. N. Pace, Spectrophotometric Determination of Protein Concentration, In Current Protocols in Protein Science, John Wiley \& Sons, Inc. 2003, pp 3.1.1-3.1.9.

This article is protected by copyright. All rights reserved. 


\section{Figure captions}

Fig. 1. CD spectra of $\mathbf{A 1}, \mathbf{A 2}$, and $\mathbf{A 3}$ in water at $298 \mathrm{~K}$. Y-axis represents mean residue molar ellipticity and X-axis represents wavelength in $\mathrm{nm}$. The peptide concentration is 40 $\mu \mathrm{M}$. Inset show the wavelength region $(207-230 \mathrm{~nm})$ that include the characteristic maxima $(217-220 \mathrm{~nm})$ for the PPII conformation in higher magnification.

Fig. 2. CD spectra of A1, A2, and $\mathbf{A 3}$ in methanol at $298 \mathrm{~K}$. The peptide concentration is 40 $\mu \mathrm{M}$.

Fig. 3. $\mathrm{CD}$ spectra of peptides $\mathbf{A 1}, \mathbf{A 2}$, and $\mathbf{A 3}$ in water (left panel) and methanol (right panel) at $298 \mathrm{~K}$ in $40-100 \mu \mathrm{M}$ concentration range. The peptides' structures are concentration independent in their molar ellipticities in both water and methanol, thus apparently, free of aggregation.

Fig. 4. CD spectra of $\mathbf{A 1}$ (left panel) and $\mathbf{A 2}$ (right panel) in water displaying temperature dependent equilibrium between different conformations. The peptide concentration is $40 \mu \mathrm{M}$.

Fig. 5. CD spectra of A1 (left panel) and A2 (right panel) displaying solvent dependent equilibrium between different conformations. The peptide concentration is $40 \mu \mathrm{M}$. The solvent composition is shown as water $(\mathrm{W})$ to methanol $(\mathrm{M})$ ratio.

This article is protected by copyright. All rights reserved. 
Table 1. Sequence of the designed nine-residue alanine-based peptides A1, A2, and A3. The $\mathrm{N}$-terminal homochiral and heterochiral diproline segment, and amino acids with charged side chains are shown in bold.

\begin{tabular}{ll}
\hline Model & Alanine-based peptides \\
\hline A1 & Ac-Pro-Pro-Ala-Lys-Ala-Lys-Ala-Lys-Ala-NH \\
A2 & Ac-Pro-Pro-Glu-Glu-Ala-Ala-Lys-Lys-Ala-NH \\
A3 & Ac-DPro-Pro-Glu-Glu-Ala-Ala-Lys-Lys-Ala--NH \\
\hline
\end{tabular}

This article is protected by copyright. All rights reserved. 
Table 2. Mean residue molar ellipticity at $222 \mathrm{~nm}$ i.e. $[\theta]_{222}$ and estimated helix content from CD spectra of A1, A2, and A3 in water and methanol.

\begin{tabular}{lllll}
\hline & Water & \multicolumn{3}{c}{ Methanol } \\
\hline & {$[\theta]_{222}$} & $\begin{array}{l}\text { estimated helix } \\
\operatorname{content}^{a}(\%)\end{array}$ & {$[\theta]_{222}$} & $\begin{array}{l}\text { estimated helix } \\
\operatorname{content}^{a}(\%)\end{array}$ \\
\hline A1 & 57.38 & 0 & -5730.46 & 20 \\
A2 & -2603.26 & 9 & -22214.72 & 76 \\
A3 & -7767.65 & 26 & -15232.78 & 52
\end{tabular}

${ }^{a}$ Helix content was calculated from the mean residue molar ellipticity at $222 \mathrm{~nm}$ i.e. $[\theta]_{222}$ using the following equation, \% helix $=100\left[[\theta]_{222} /\{-39500(1-2.57 / \mathrm{n})\}\right]$, where $\mathrm{n}$ is the number of peptide bonds [20]. 


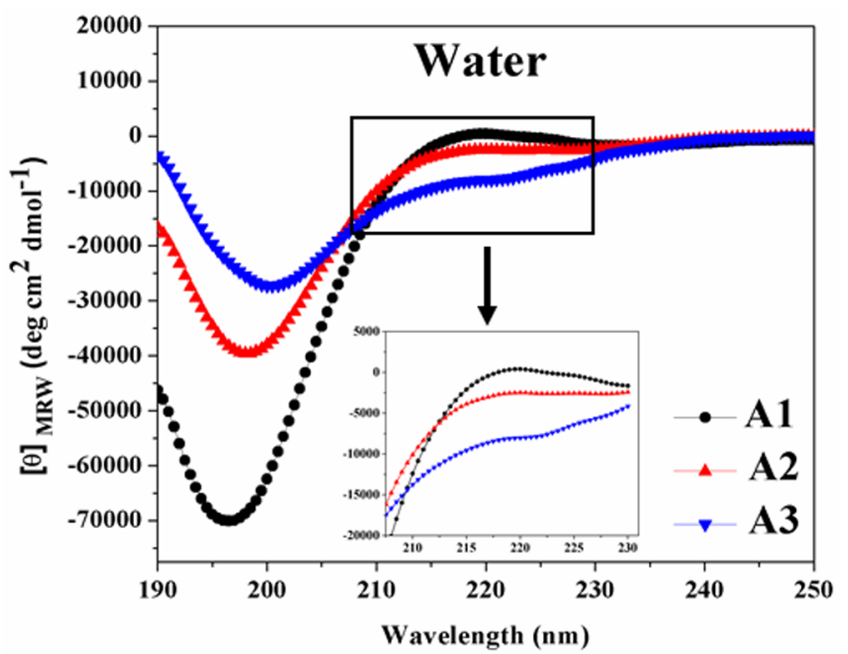

PSC_3005_F1.tif

This article is protected by copyright. All rights reserved. 


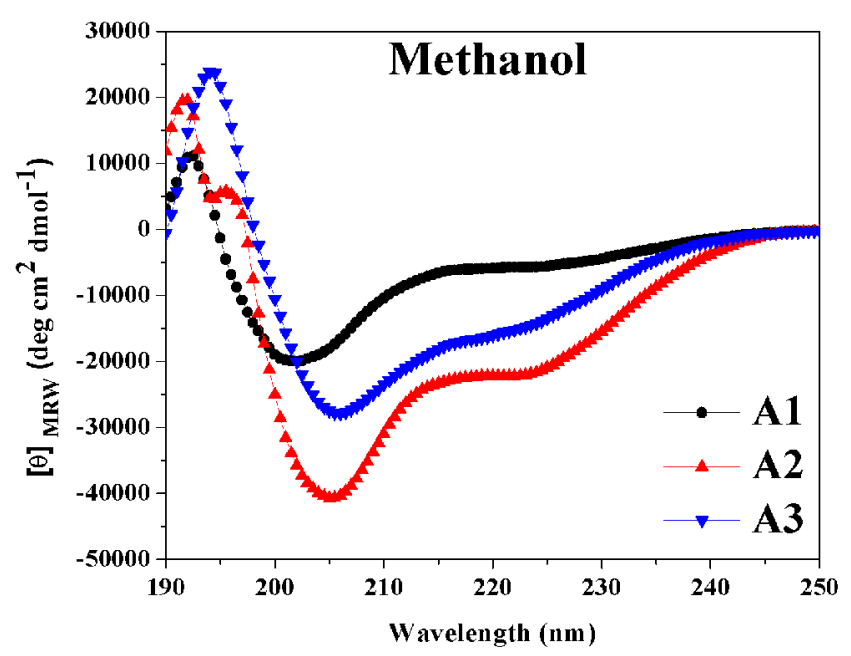

PSC_3005_F2.tif

This article is protected by copyright. All rights reserved. 

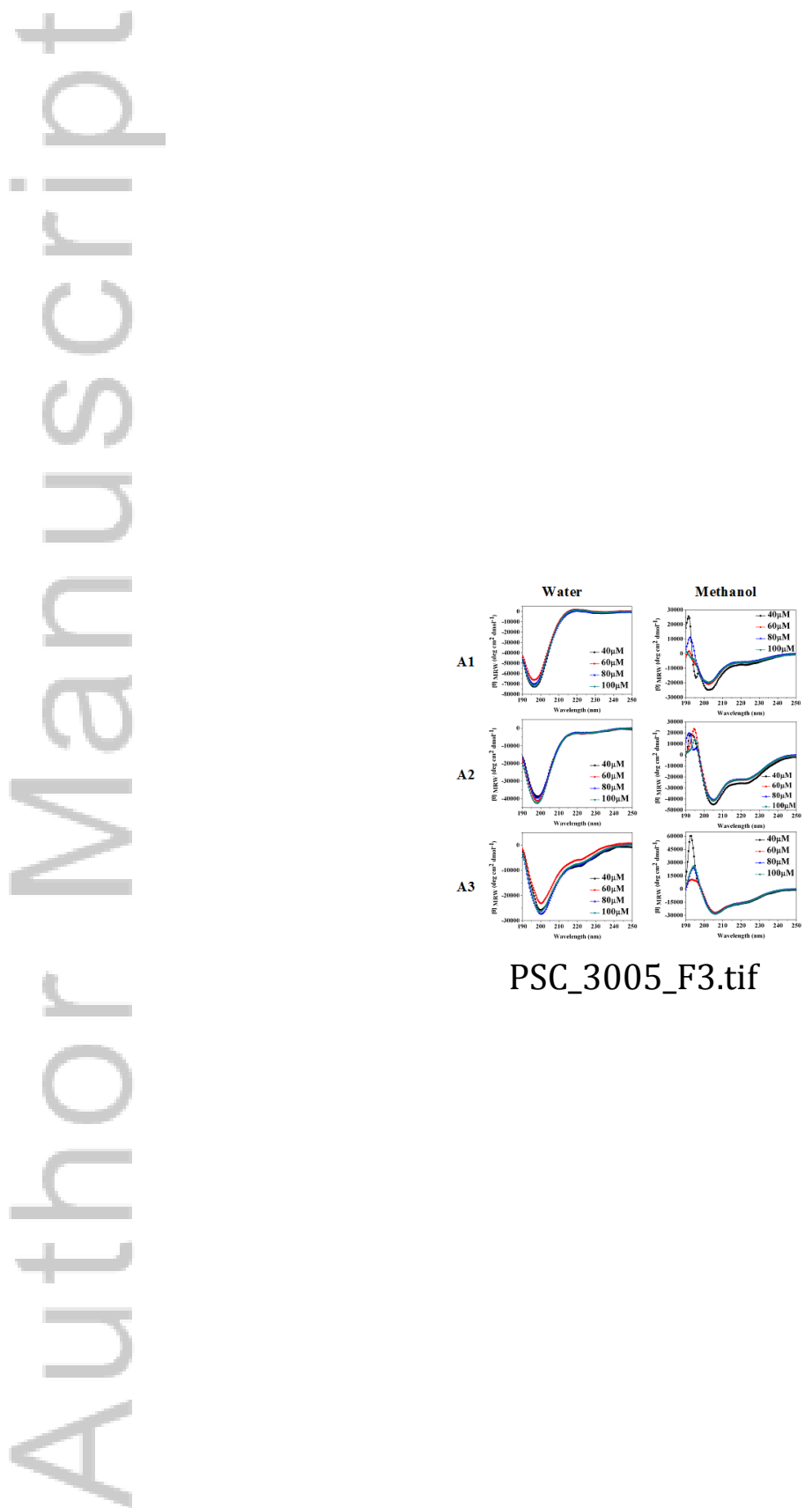

PSC_3005_F3.tif

This article is protected by copyright. All rights reserved. 

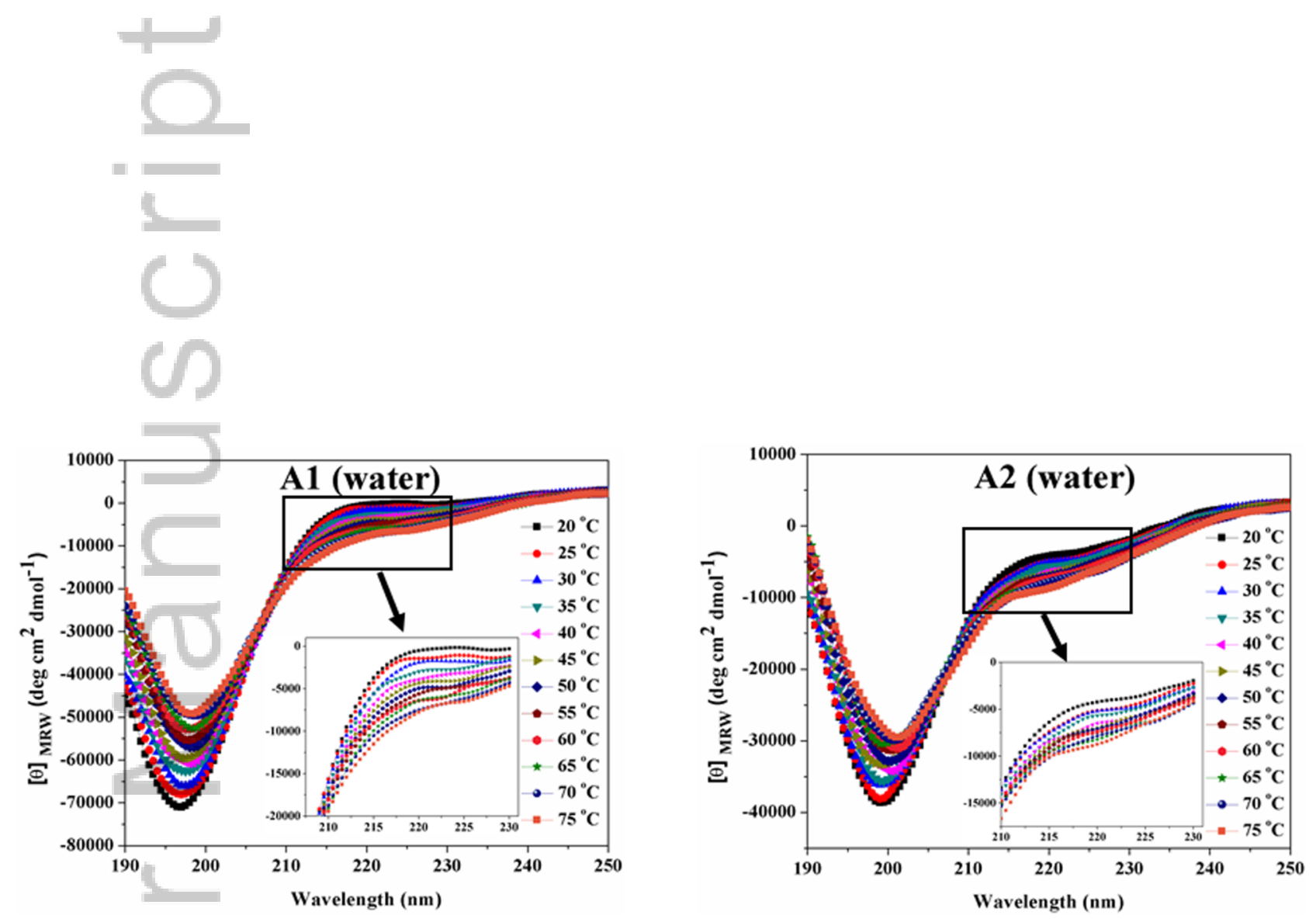

PSC_3005_F4.tif

This article is protected by copyright. All rights reserved. 

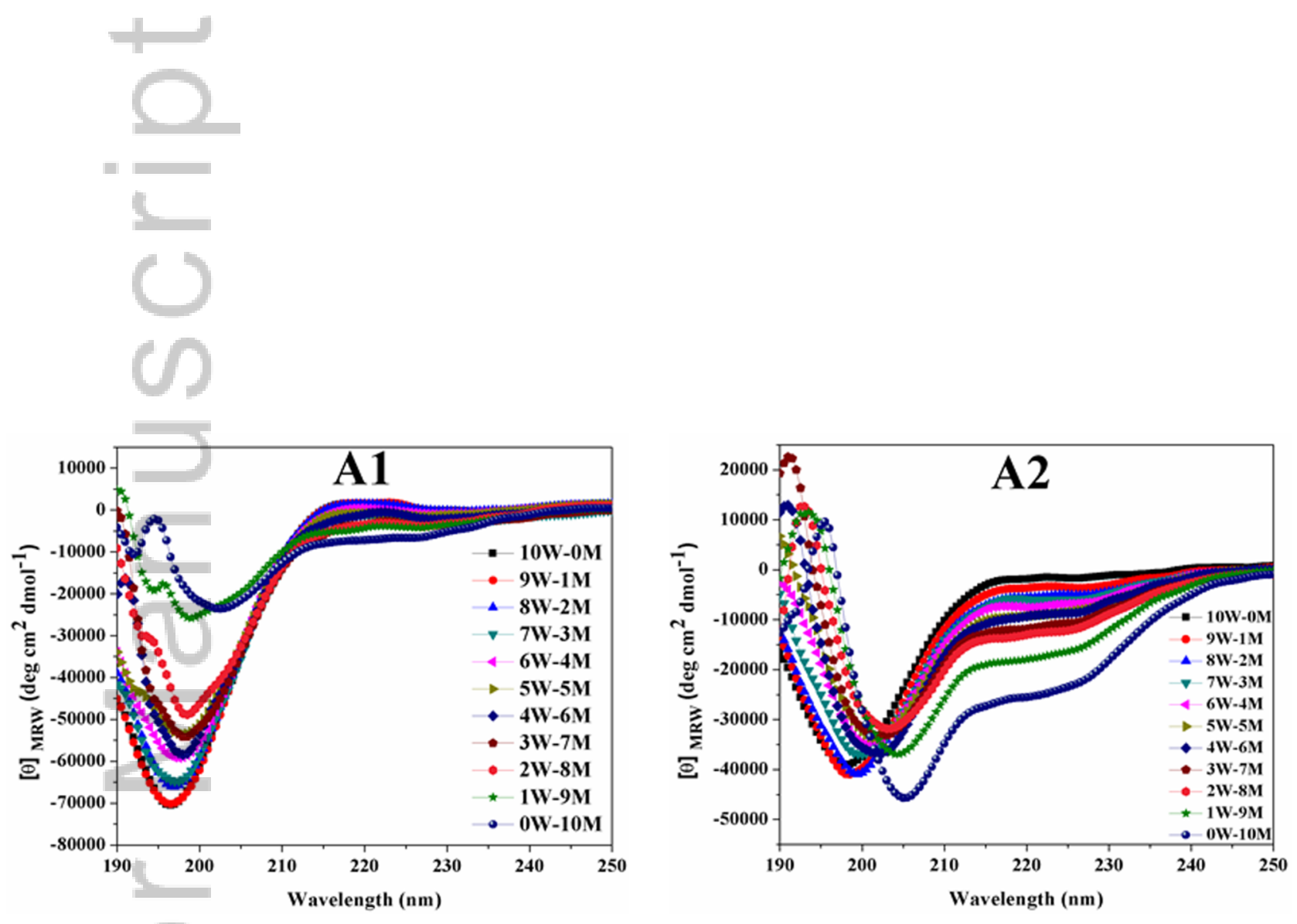

PSC_3005_F5.tif

This article is protected by copyright. All rights reserved. 